\title{
Changes in the liver histomorphology, catalase and glutathione peroxidase activity in the serum and liver homogenate of normal and monosodium glutamate-intoxicated rats co-treated with artemether-lumefantrine
}

\begin{abstract}
Artemether-lumefantrine (AL), an artemisinin-based anti-malarial, and monosodium glutamate (MSG), a flavor enhancer, respectively mediated oxidative stress with potential interactive effects in non-malarial-infected-hosts. Thus, changes in the liver histomorphology, catalase (CAT) and glutathione peroxidase (GPx) activity in the serum and liver homogenate of normal and monosodium glutamate-intoxicated rats co-treated with artemether-lumefantrine were investigated. Thirty rats randomly sectioned into six $(n=5)$ were exposed to feed and water in addition to nothing (Group A, control), therapeutic dose of AL (Group B), overdose (therapeutic dose $\times 5$ ) of AL (Group C), MSG, at $8000 \mathrm{mg} / \mathrm{kg}$ body weight (Group D), therapeutic dose of AL plus MSG (Group E) and overdose of AL plus MSG (Group F). Rats exposed to MSG either alone or together with overdose of AL had overriding reduction in the serum and liver homogenate CAT and Gpx activities, computed Gpx:CAT and CAT:Gpx ratios, and severe histological changes compared to the control and others, suggesting significant adverse effect of overdose of AL together with MSG on the rats' liver morphology and in the serum and liver homogenate CAT and GPx activities. Thus, exposure of normal rats to, in particular, overdose of AL together with MSG, exerted significant adverse influence on the rats' liver by way of compromised liver morphology and antioxidant capacity. It was admonished that non-malaria parasite infected rats should not be exposed to AL, irrespective of dose, either alone or together with intoxicating dose of MSG. The possible implications of this study in humans evoke further studies, hence are recommended.
\end{abstract}

Keywords: artemesinin-based, oxidative stress, therapeutic dose, liver morphology, antioxidant capacity
Volume 4 Issue 2 - 2019

\author{
Emmanuel Obi,Anthony Cemaluk C \\ Egbuonu \\ Department of Biochemistry, Michael Okpara University of \\ Agriculture Umudike, Nigeria
}

\begin{abstract}
Correspondence: Egbuonu Anthony Cemaluk C, Department of Biochemistry, College of Natural Sciences, Michael Okpara University of Agriculture Umudike, Nigeria, Tel +23480-3636-
\end{abstract} 6565, Email tonycemalukegbuonu@yahoo.com

Received: January 26, 2019 | Published: April 02, 2019

\begin{abstract}
Abbreviations: AL, artemether-lumefantrine; MSG, monosodium glutamate; CAT, catalase; GPx, glutathione peroxidase; ACTs, artemisinin-based combination therapies; WHO, world health organization; $\mathrm{CYP}_{450}$, cytochrome $\mathrm{p}_{450} ; \mathrm{H}_{2} \mathrm{O}_{2}$, hydrogen peroxide; $\mathrm{IU} / \mathrm{L}$, international unit per litre; GSH, glutathione; NADPH, reduced nicotinamide adenine dicnucleotide phosphate; $\mathrm{NADP}^{+}$, oxidized nicotinamide adenine dinucleotide phosphate; NM, nanometer; ANOVA, analysis of variance; SPSS, statistical package for social sciences; SEM, standard error of mean
\end{abstract}

\section{Introduction}

Artemisinin-based combination therapies (ACTs), a first line anti-malarial in drug resistant malarial parasite endemic sub-Saharan African countries, including Nigeria. ${ }^{1-3}$ could, aside delaying drug resistance, ${ }^{2,4}$ exert early parasitological response while the partner drug could prevent recrudescence by slowly eliminating the remaining malaria parasites. ${ }^{4,5}$ The commonly used artemether-lumefantrine, as the other artemesisnin-based combination therapies, acts by generating free radicals (pro-oxidants) that kill the malaria parasites. ${ }^{6-8}$ Monosodium glutamate (MSG), a flavor enhancer with unique taste widely used in canned foods, ${ }^{9-11}$ could induce toxic influences and oxidative stress in animals. ${ }^{12-17}$ In particular, oxidative stress which could cause even base damage and strand breaks in DNA, ${ }^{18}$ is implicated in the etiology of many diseases. ${ }^{19-22}$ Thus, the possible interactive effects of MSG with artemether-lumefantrine on the antioxidant response status of animals may be significant, particularly in non-malaria-parasite-infested host. This may be notable in the liver which serves as the major detoxification organ, ${ }^{23,24}$ using cytochrome $\mathrm{P}_{450}\left(\mathrm{CYP}_{450}\right)$, glutathione peroxidase, and catalase..$^{24,25}$

Further to the above, as an over the counter drug a possibility of abuse of AL exists. With reported self-medication with antimalarials, ${ }^{26}$ possibility of overdose and even prolonged intake of AL exists. Also, possibility of co-intake of artemether-lumefantrine with monosodium glutamate-flavour enhanced fast foods, even at an overdose and in absence of malaria infection, exits. That notwithstanding, there is paucity in literature as regards possible effect on the antioxidant status following use or abuse of $\mathrm{AL}$ either alone or in combination with intoxicating dose of MSG particularly in absence of malaria parasite infection. These warranted this study aimed at investigating changes in the liver histomorphology, catalase and glutathione peroxidase activity in the serum and liver homogenate of normal and monosodium glutamate-intoxicated rats co-treated with artemetherlumefantrine. Altered catalase and glutathione peroxidase activity indicated induction of oxidative stress while the changes in organ histology could confirm compromised organ function..$^{27-29}$ 


\section{Materials and methods}

The artemether-lumefantrine $(20: 120 \mathrm{mg})$ combination used in this study was procured from a recognized medical representative in Umuaha, Abia State, Nigeria. Monosodium glutamate (99 \% purity) was purchased from Umuahia market, Abia state, Nigeria. Thirty (30) male Wistar rats weighing 89-183g were bought from a commercial breeder at Nsukka, Enugu state Nigeria and transported in a well ventilated metal cages to the animal house of the department of biochemistry, Michael Okpara University of Agriculture, Umudike, Abia State, Nigeria. All animals were allowed a 14-day period of acclimatization before commencement of the experiment. The rats were randomly sectioned into six (6) groups of five rats each and respectively exposed freely to feed (vital feed pellets) and portable tap water in addition to nothing (Group A, control), therapeutic dose of AL (Group B), overdose of AL (Group C), MSG (Group D), therapeutic dose of AL plus MSG (Group E) and overdose of AL plus MSG (Group F). The exposure was oral using a gavage. Artemether-lumefantrine overdose was calculated as therapeutic dose for $70 \mathrm{~kg}$ man multiplied by 5 . The administration of artemether-lumefantrine was twice each day after $8 \mathrm{hrs}$ interval, in line with the prescription format of its dosage in respect to a $70 \mathrm{~kg}$ man given in volume (prepared by dissolving adult dose (4 tablets) of artemether-lumefantrine in $100 \mathrm{ml}$ of distilled water) corresponding to the rats weight according to manufacturer's instruction. In brief, the first and second dose exposures were eight hours apart while the third dose exposure was 24 hours after the first or 16 hours after the second whereas the remaining doses (fourth, fifth and sixth) were given 12 hours apart. Rats intoxication with MSG was achieved at $8000 \mathrm{mg} / \mathrm{kg}$ body weight and by daily exposure for 7 days according to Mariyamma et al., ${ }^{13}$ as supported by other studies..$^{30-33}$

\section{Ethical consideration}

Throughout the experimentation (acclimatization and exposure periods), all rats were housed at $25^{\circ} \mathrm{C}$ in stainless steel cages under normal daylight/day cycle and humid tropical conditions. The rats were allowed free access to rat feed (vital feed pellets) and tap water and were conditioned throughout the process according to the guidelines approved by the department official committee on animal use, Michael Okpara University of Agriculture, Umudike on handling of experimental rats.

\section{Sacrifice and sample collection}

After 7 days, the rats were sacrificed the next day after overnight fast by ocular puncture and the blood sample of the respective rats was collected into a clean non-anticoagulated polystyrene tube, allowed to clot and centrifuged at 3000rpm for 5 minutes and the serum collected and stored in a refrigerator until used. The liver of the respective rat was excised and the section for the histological study was placed in a tube containing formalin. The remaining liver section was rinsed in iced-cold sucrose, and a $10 \% \mathrm{w} / \mathrm{v}$ homogenate was prepared from it using $0.15 \mathrm{M} \mathrm{KCl}$ as buffer to obtain the supernatant sample after centrifugation. ${ }^{31}$

\section{Measurement of oxidative stress markers}

Serum and liver homogenate activity of the catalase was determined by the method as described by $\mathrm{Sinha}^{34}$ based on the principle that dichromate in acetic acid was reduced to chromic acetate when heated in presence of hydrogen peroxide $\left(\mathrm{H}_{2} \mathrm{O}_{2}\right)$ with the formation of per chromic acid as an unstable intermediate. In brief, to $0.9 \mathrm{ml}$ of phosphate, $0.1 \mathrm{ml}$ of serum (or liver homogenate) and $0.4 \mathrm{ml}$ of $\mathrm{H}_{2} \mathrm{O}_{2}$ were added. The reaction was initiated by adding $2 \mathrm{ml}$ of dichromate acetic acid mixture. The tubes were kept in a boiling water bath for 10 minutes, cooled and the colour developed was read at $530 \mathrm{~nm}$ at intervals of 30 minutes for $2 \mathrm{hrs}$. Standards in the concentration range of $20-100$ micromoles were processed for the test. The catalase activity was calculated as micromoles of $\mathrm{H}_{2} \mathrm{O}_{2}$ utilised/second expressed as international unit per litre (IU/L).

Serum and liver homogenate glutathione peroxidase activity was determined by the method of Paglia et al., ${ }^{35}$ based on the principle that glutathione peroxidase (Gpx) catalyzes the oxidation of glutathione (GSH). In brief, a known volume, $0.05 \mathrm{ml}$ of serum (or liver homogemate) was diluted with $2 \mathrm{ml}$ of diluting reagent. To $50 \mu \mathrm{l}$ of either the diluted sample or blank was mixed with $1 \mathrm{ml}$ of reagent 1 (glutathione+glutathione reductase+NADPH) and reagent 2 (cumene hydroperoxide) respectively. The initial absorbance of the test or the blank was respectively read after $1 \mathrm{~min}$ and the timer started simultaneously. In the presence of glutathione reductase and NADPH the oxidized glutathione is immediately converted to the reduced form with a concomitant oxidation of NADPH to NADP ${ }^{+}$. The decrease in absorbance at $340 \mathrm{~nm}$ was measured by reading absorbencies after 1 and 2 minutes intervals. Glutathione peroxidase activity was calculated from the formulae below:

$$
\operatorname{GPx}(\mathrm{IU} / \mathrm{L})=8412 \times \Delta \mathrm{A} 340 \mathrm{~nm} / \text { minute. }
$$

\section{Histopathological examination}

The respective liver section of the rats collected for histopathological studies was prepared as previously reported. ${ }^{36}$ In brief, the respective liver sections were fixed in 10\% phosphate buffered formalin for 48 hours, trimmed, dehydrated in 4 grades of alcohol $(70 \%, 80 \%, 90 \%$ and $100 \%$ or absolute alcohol), cleared in 3 grades of xylene and embedded in molten wax. On solidifying, the blocks were sectioned into $5 \mu \mathrm{m}$ thickness with a rotary microtome, floated in water bathe and incubated at $60^{\circ} \mathrm{C}$ for 30 minutes. The $5 \mu \mathrm{m}$ thick kidney sections were subsequently cleared in 3 grades of xylene and rehydrated in 3 grades of alcohol $(90 \%, 80 \%$ and $70 \%)$. The sections were then stained with Hematoxylin for 15 minutes and blued (stained blue) with ammonium chloride. Differentiation was done with $1 \%$ acid alcohol before counterstaining with Eosin. Permanent mounts were made on degreased glass slides using a permanent DPX mountant (Model 44581, Sigma-Aldrich, United Kingdom). The prepared slides were examined with a Motic ${ }^{\mathrm{TM}}$ compound light microscope at various magnifications $(\times 4, \times 10$ and $\times 40)$ of the objective lenses. The photomicrographs were taken using a Motic ${ }^{\mathrm{TM}} 9.0$ megapixels microscope camera at $\times 400$ magnification.

\section{Calculation of diagnostic ratios and change relative to groups}

Diagnostic ratios were calculated from the result of corresponding parameters as obtained in this study. The calculation of change relative to any group was as developed and severally used..$^{28,37-39}$

Change relative to either control or MSG group was calculated using the relation:

Change relative to $\mathrm{K}(\%)=(\mathrm{V}-\mathrm{K}) / \mathrm{K} \times 100$

Where, $\mathrm{K}$ represents the constant group hence constant value and $\mathrm{V}$ represents the variable group hence variable values. 


\section{Statistical analysis}

The data were subjected to one way analysis of variance (ANOVA) using Statistical package for social sciences (SPSS) version 20.0. Results were expressed as mean \pm standard error of mean (SEM). Difference was accepted as significant at $\mathrm{p}<0.05$.

\section{Results}

The result as shown on Table 1 revealed that the serum catalase activity of rats in the other groups as compared to rats in the control was lower $(\mathrm{p}<0.05)$. The decrease in serum catalase activity relative to the control group was highest in the MSG only group (58.38\%) followed by that in rats exposed to overdose of artemether-lumefantrine combination (AL) alone $(46.70 \%)$ and least in the therapeutic dose of AL (11.68\%). However, the increase relative to the MSG group aside the control (140.24\%) was highest in the therapeutic dose of AL $(112.20 \%)$.

The result as shown on Table 2 revealed that rats exposed to MSG alone had lower $(\mathrm{p}<0.05)$ liver homogenate catalase activity compared to the control. However, the liver catalase activity of rats in the therapeutic dose of AL, overdose of AL and overdose of AL + MSG were higher $(p<0.05)$ than that of the rats in the control. The increase in catalase activity relative to the control was highest in the therapeutic dose of AL treated group of rats $(61.99 \%)$ followed by that of rats in the overdose of AL (39.18\%). The increase in liver catalase activity relative to the MSG treated group was highest in the rats exposed to the therapeutic dose of AL alone (134.75\%).
The result as shown on Table 3 revealed that rats exposed to MSG (either alone or together with overdose of AL) had overriding reduction in the serum Gpx activity of the rats compared to the control and the other test groups. The decrease in Gpx activity relative to the control was highest in MSG treated group of rats (64.34\%). The increase in serum Gpx activity relative to the MSG treated group was highest in the rats exposed to overdose of AL+MSG (349.10).

The result as shown on Table 4 revealed that the Gpx activity in the liver homogenate of rats in the other groups as compared to rats in the control was lower $(\mathrm{p}<0.05)$. The decrease in liver Gpx activity relative to the control group was highest in the MSG only group (33.63) followed by that in rats exposed to overdose of AL+MSG (22.47) and least in the overdose of AL $(1.74 \%)$. However, the increase relative to the MSG group aside the control (50.67) was highest in the overdose of AL treated group (48.05).

The result as shown on Table 5 revealed overriding higher computed serum Gpx: CAT ratio but lower CAT: Gpx ratio in rats exposed to overdose of AL together with intoxicating dose of MSG compared with the other groups including the control and the MSG alone groups.

The result as shown on Table 6 revealed higher $(\mathrm{p}<0.05)$ computed liver CAT: Gpx ratio but lower $(\mathrm{p}<0.05)$ Gpx: CAT ratio in the liver homogenate of rat in the various groups compared to rats in the control and MSG groups. The observation relative to rats in either the control or the MSG group was highest in the group of rats exposed to the therapeutic dose of AL.

Table I Changes in the catalase activity in the serum of normal and monosodium glutamate-intoxicated rats co-treated with artemether-lumefantrine

\begin{tabular}{llll}
\hline Groups & CAT (IU/L) & Change relative to the control (\%) & Change relative to MSG group (\%) \\
\hline A: Control (feed + water only) & $3.94+0.13$ & 0 & 140.24 \\
B:Therapeutic dose of AL & $3.48+0.13$ & -11.68 & 112.2 \\
C: Overdose of AL & $2.10+0.09$ & -46.70 & 28.05 \\
D: MSG (8000 mgkg'bwt) & $1.64+0.15$ & -58.38 & 0 \\
E:Therapeutic dose of AL + MSG & $3.37+0.13$ & -14.47 & 105.49 \\
F: Overdose of AL + MSG & $2.35+0.15$ & -40.36 & 43.29 \\
\hline
\end{tabular}

Values are mean \pm SEM for $n=5$. + denotes higher by; - denotes lower by. Difference considered statistically significant at $p<0.05$

Table 2 Changes in the catalase activity in the liver homogenate of normal and monosodium glutamate-intoxicated rats co-treated with artemether-lumefantrine

\begin{tabular}{llll}
\hline Groups & CAT (IU/L) & Change relative to the control (\%) & Change relative to MSG group (\%) \\
\hline A: Control (feed + water only) & $1.71+0.14$ & 0 & 44.92 \\
B: Therapeutic dose of AL & $2.77+0.33$ & 61.99 & 134.75 \\
C: Overdose of AL & $2.38+0.16$ & 39.18 & 101.69 \\
D: $M S G\left(8000 \mathrm{mgkg}{ }^{-1} \mathrm{bwt}\right)$ & $1.18+0.09$ & -30.99 & 39.83 \\
E: Therapeutic dose of AL + MSG & $1.65+0.20$ & -3.51 & 63.56 \\
F: Overdose of AL + MSG & $1.93+0.15$ & 12.87 &
\end{tabular}

Values are mean \pm SEM for $n=5$. + denotes higher by; - denotes lower by. Difference considered statistically significant at $p<0.05$

Changes in the liver histomorphology of normal and monosodium glutamate-intoxicated rats co-treated with artemether-lumefantrine

Compared to rats in the control and in the therapeutic dose groups, that showed normal hepatic lobules composed of normal hepatocytes arranged in interconnecting cords around the central vein in their histo-architecture (Figure 1 \& Figure 2), mild to moderate changes including hepatocellular necrosis observed in the liver sections of the other groups (Figure 3-5) were moderate to severe in the group of rats exposed to overdose of AL together with MSG (Figure 6). 
Table 3 Changes in the glutathione peroxidase (GPx) activity in the serum of normal and monosodium glutamate-intoxicated rats co-treated with artemetherlumefantrine

\begin{tabular}{llll}
\hline Groups & GPx (IU/L) & Change relative to the control (\%) & Change relative to MSG group (\%) \\
\hline A: Control (feed + water only) & $4.60+0.16$ & 0 & 175.45 \\
B:Therapeutic dose of AL & $3.82+0.17$ & -16.96 & 128.74 \\
C: Overdose of AL & $4.62+0.98$ & 0.43 & 0 \\
D: MSG (8000 mgkg-bwt) & $1.64+0.57$ & -64.34 & 176.65 \\
E:Therapeutic dose of AL + MSG & $3.66+0.16$ & -20.43 & 349.1 \\
F: Overdose of AL + MSG & $7.50+0.15$ & 63.04 &
\end{tabular}

Values are mean \pm SEM for $n=5$. + denotes higher by; - denotes lower by. Difference considered statistically significant at $p<0.05$

Table 4 Changes in the glutathione peroxidase (GPx) activity in the liver homogenate of normal and monosodium glutamate-intoxicated rats co-treated with artemether-lumefantrine

\begin{tabular}{llll}
\hline Groups & GPx (IU/L) & Change relative to the control (\%) & Change relative to MSG group (\%) \\
\hline A: Control (feed + water only) & $20.07+2.34$ & 0 & 50.67 \\
B: Therapeutic dose of AL & $17.51+0.70$ & -12.76 & 31.46 \\
C: Overdose of AL & $19.72+0.71$ & -1.74 & 48.05 \\
D: $M S G(8000$ mgkg-'bwt) & $13.32+0.54$ & -33.63 & 18.39 \\
E: Therapeutic dose of AL + MSG & $15.77+0.24$ & -21.43 & 16.32 \\
F: Overdose of AL + MSG & $15.56+0.31$ & -22.47 &
\end{tabular}

Values are mean \pm SEM for $n=5+$ denotes higher by; - denotes lower by. Difference considered statistically significant at $p<0.05$

Table 5 Changes in the catalase to glutathione peroxidase (CAT:GPx) and glutathione peroxidase to catalase (GPx:CAT) ratios in the serum of normal and monosodium glutamate-intoxicated rats co-treated with artemether-lumefantrine

\begin{tabular}{|c|c|c|c|}
\hline Groups & $\begin{array}{l}\text { CAT:GPx } \\
\text { (GPx:CAT) }\end{array}$ & $\begin{array}{l}\text { Change relative to the control } \\
(\%)\end{array}$ & $\begin{array}{l}\text { Change relative to MSG group } \\
(\%)\end{array}$ \\
\hline A: Control (feed + water only) & $0.86(1.17)$ & $0.00(0.00)$ & $-12.24(+14.71)$ \\
\hline B:Therapeutic dose of $A L$ & $0.91(1.10)$ & $+5.81(-5.98)$ & $-7.14(+7.84)$ \\
\hline C: Overdose of AL & $0.45(2.20)$ & $-47.6(+88.03)$ & $-54.08(+115.69)$ \\
\hline D: MSG(8000 mgkg-1bwt) & $0.98(1.02)$ & $+13.95(-12.82)$ & $0.00(0.00)$ \\
\hline E:Therapeutic dose of $A L+M S G$ & $0.92(1.09)$ & $+6.98(-6.84)$ & $-6.12(+6.86)$ \\
\hline $\mathrm{F}:$ Overdose of $\mathrm{AL}+\mathrm{MSG}$ & $0.31(3.19)$ & $-63.95(+172.65)$ & $-68.37(+212.75)$ \\
\hline
\end{tabular}

Values are mean \pm SEM for $n=5$. + denotes higher by; - denotes lower by. Difference considered statistically significant at $p<0.05$

Table 6 Changes in the catalase to glutathione peroxidase (CAT:GPx) and glutathione peroxidase to catalase (GPx:CAT) ratios in the liver homogenate of normal and monosodium glutamate-intoxicated rats co-treated with artemether-lumefantrine

\begin{tabular}{llll}
\hline Groups & $\begin{array}{l}\text { CAT:GPX } \\
\text { (GPX:CAT) }\end{array}$ & $\begin{array}{l}\text { Change relative to the control } \\
(\%)\end{array}$ & $\begin{array}{l}\text { Change relative to MSG group } \\
\text { (\%) }\end{array}$ \\
\hline A: Control (feed+water only) & $0.09($ II.74) & $0.00(0.00)$ & $77.78(-44.02)$ \\
B: Therapeutic dose of AL & $0.16(6.32)$ & $77.78(-46.17)$ & $33.33(-26.57)$ \\
C: Overdose of AL & $0.12(8.29)$ & $33.33(-29.39)$ & $0.00(0.00)$ \\
D: MSG(8000 mgkg-bwt) & $0.09($ II.29) & $0.00(-3.83)$ & $11.11(-15.32)$ \\
E: Therapeutic dose of AL + MSG & $0.10(9.56)$ & $11.11(-18.57)$ & $0.33(-28.61)$
\end{tabular}

Values are mean \pm SEM for $n=5$. + denotes higher by; - denotes lower by. Difference considered statistically significant at $p<0.05$

Citation: Obi E, Egbuonu ACC. Changes in the liver histomorphology, catalase and glutathione peroxidase activity in the serum and liver homogenate of normal and monosodium glutamate-intoxicated rats co-treated with artemether-lumefantrine. Int J Mol Biol Open Access. 20I9;4(2):67-73. DOI:

10.15406/ijmboa.2019.04.00099 


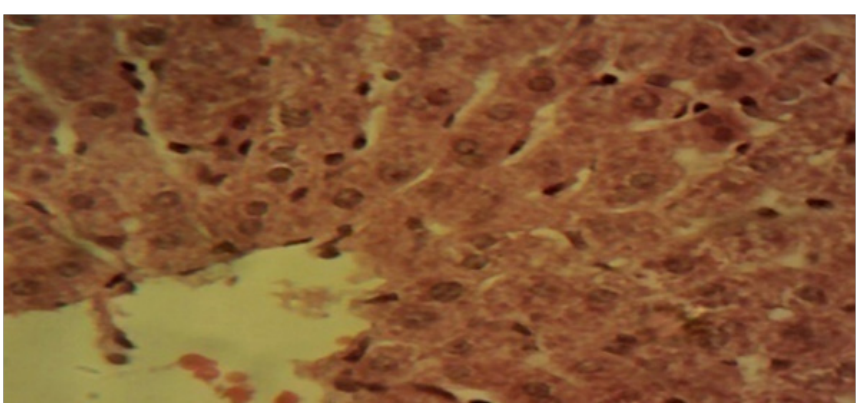

Figure I Photomicrograph of the liver sections from rats in the contro showing normal hepatic lobules composed of normal hepatocytes arranged in interconnecting cords around the central vein $(\times 400)$.

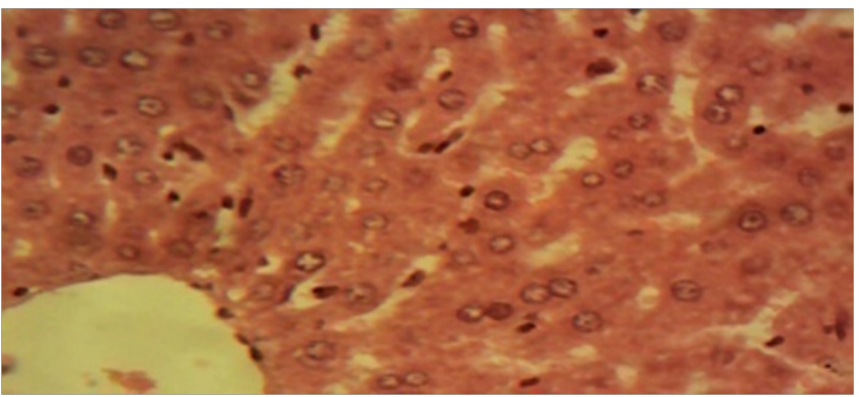

Figure 2 Photomicrograph of the liver of the therapeutic dose animal showing normal hepatic histomorphology for laboratory rodents $(\times 400)$.

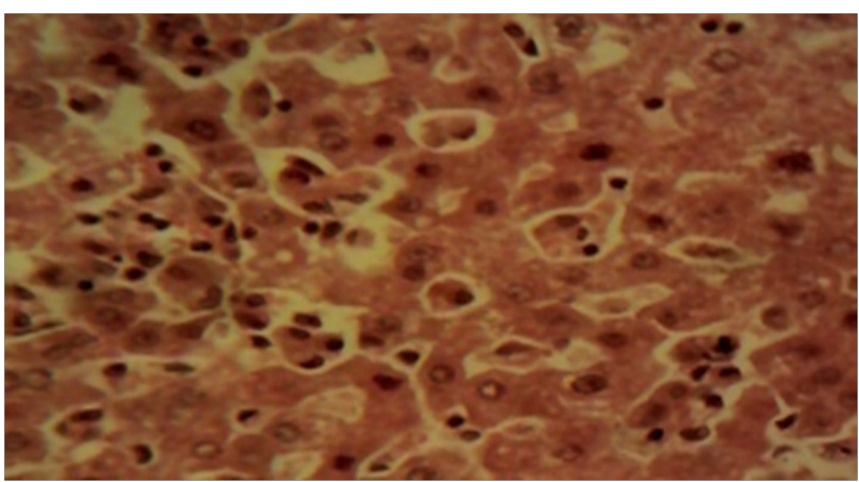

Figure 3 Photomicrograph of the liver of the overdose animal showing multifocal areas of hepatocellular necrosis $(\times 400)$.

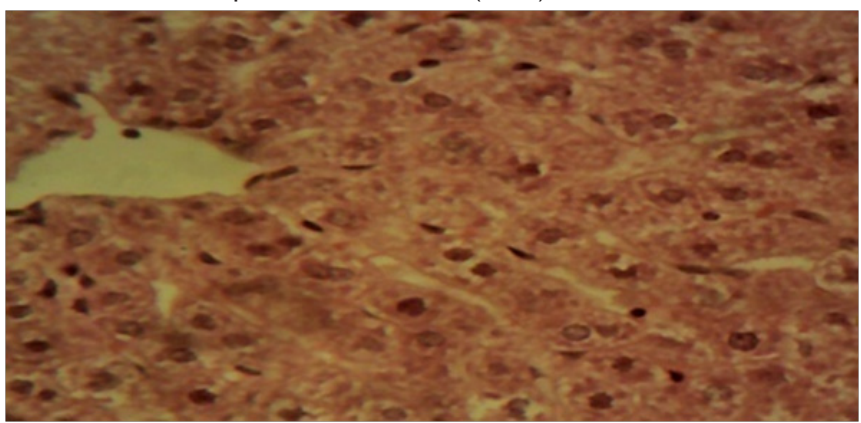

Figure 4 Photomicrograph of the liver of the MSG only animal showing mild to moderate diffuse, hepatocellular degeneration and necrosis involving all zones of the hepatic lobules $(\times 400)$.

\section{Discussion}

Artemether-lumefantrine (AL), an artemisinin-based anti-malarial, and monosodium glutamate (MSG), a flavor enhancer, respectively mediated oxidative stress with potential interactive effects in nonmalarial-infected-hosts. Oxidative stress is fundamental in diseased conditions, ${ }^{36,40,41}$ thus, changes in the liver histomorphology, catalase (CAT) and glutathione peroxidase (GPx) activity in the serum and liver homogenate of normal and monosodium glutamate-intoxicated rats co-treated with artemether-lumefantrine were investigated. Monosodium glutamate intoxication of the rats was according to Mariyamma et al. ${ }^{13}$

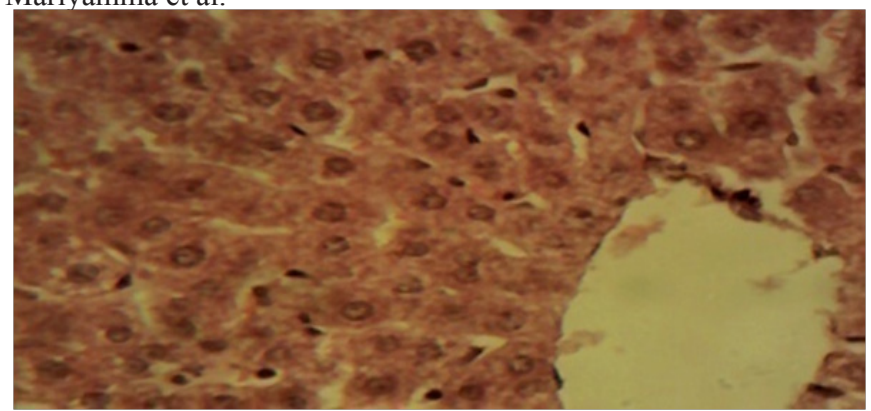

Figure 5 Photomicrograph of the liver of the therapeutic dose + MSG animal showing mild diffuse, hepatocellular degeneration involving all zones of the hepatic lobule $(\times 400)$.

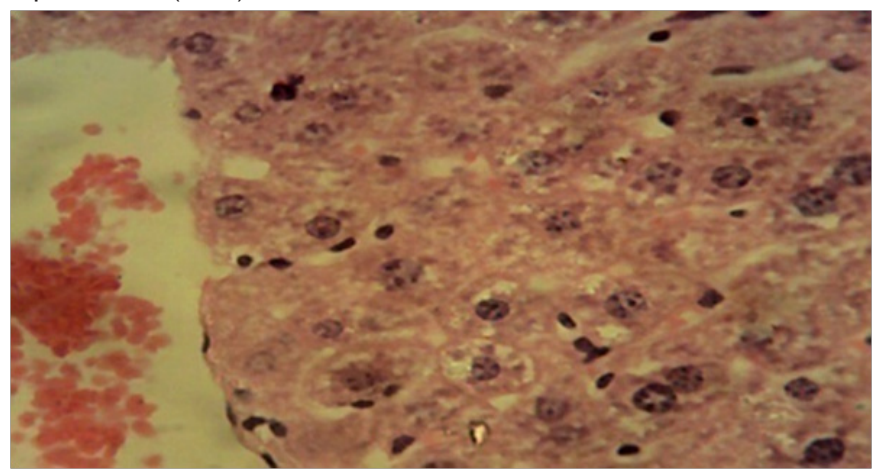

Figure 6 Photomicrograph of the liver of the overdose + MSG animal showing moderate to severe diffuse, hepatocellular degeneration and necrosis involving all zones of the hepatic lobule $(\times 400)$.

Generally, catalase and glutathione peroxidase catalyze the conversion of hydrogen peroxide to water and gaseous oxygen. ${ }^{42}$ The result of the study on serum and liver homogenate catalase activity of rats revealed a decrease in activity which was, relative to the control, highest in the MSG only group followed by that in rats exposed to overdose of artemether-lumefantrine (AL) alone and least in the therapeutic dose of AL (Table 1 \& Table 2), suggesting overriding induction of oxidative stress in the rats following exposure to either MSG or overdose of AL. Lower $(p<0.05)$ CAT activity in MSGexposed rats confirmed induction of oxidative stress in the MSGtreated rats. ${ }^{36}$ Decreased serum catalase activity ${ }^{43,44}$ and organ catalase activity $^{8}$ indicated clinical signs of artemether-lumefantrine-induced toxicity. Artemether monotherapy also decreased liver catalase activity of the animals. ${ }^{45}$ Decreased CAT activity in the rats, as observed in this study, may have resulted from increased involvement of the enzyme in antioxidant defense response following MSG-induced oxidative stress. ${ }^{46}$ Apparently, the free radicals (oxidant) produced, particularly by either MSG or overdose of AL may have overwhelmed the rats' antioxidant capacity via catalase enzyme activity which resulted to the depletion as observed. ${ }^{47,48}$

However, rats exposed to MSG (either alone or together with overdose of AL) had overriding reduction in the serum Gpx activity of the rats compared to the control and the other test groups, suggesting

Citation: Obi E, Egbuonu ACC. Changes in the liver histomorphology, catalase and glutathione peroxidase activity in the serum and liver homogenate of normal and monosodium glutamate-intoxicated rats co-treated with artemether-lumefantrine. Int J Mol Biol Open Access. 2019;4(2):67-73. DOI:

10.15406/ijmboa.2019.04.00099 
significant adverse effect of overdose of AL together with MSG on the serum and liver homogenate GPx activity of the rats. The observation on the GPx activity of the rats could be attributed to oxidant effect of MSG and artemether-lumafantrine that probably overwhelmed the antioxidant capacity via GPx activity of the rats in the reported groups. Glutathione peroxidase scavanges $\mathrm{H}_{2} \mathrm{O}_{2}{ }^{49}$ and while further confirming MSG-induction of oxidative stress in the rats, the decreased GPx activity as observed could be resultant to the role of GPx as a second line of antioxidant defense mechanism following perhaps the overwhelmed antioxidant capacity of CAT, the first line of antioxidant defense mechanism. Decreased organ glutathione peroxidase activity ${ }^{8}$ indicated artemether-lumefantrine-related toxicity. The overriding higher $(\mathrm{p}<0.05)$ computed serum Gpx: CAT ratio but lower CAT:Gpx ratio (or higher $(\mathrm{p}<0.05)$ computed liver homogenate CAT:Gpx ratio but lower $(\mathrm{p}<0.05)$ Gpx:CAT ratio) in rats exposed to overdose of AL together with intoxicating dose of MSG compared with the other groups showed similar trend in apparent support of overriding adverse influence of MSG either alone or together with overdose of AL on the antioxidant capacity of the rats.

Toxic influence on the liver (including liver necrosis) of infected and uninfected rats following high doses of artemether has been reported. ${ }^{50}$ These connoted an overriding adverse influence of MSG together with overdose of AL on the hepatic histomorphology of rats in support of the result of this study obtained from the serum and liver homogenate of the rats.

\section{Conclusion}

Thus, exposure of normal rats to, in particular, overdose of AL together with MSG, exerted significant adverse influence on the rats' liver by way of compromised liver morphology and antioxidant capacity. The study necessitated the admonition that non-malaria parasite infected rats should not be exposed to $\mathrm{AL}$, irrespective of dose, either alone or together with intoxicating dose of MSG. The possible implications of the result of this study in humans evoke further studies, hence are recommended.

\section{Acknowledgments}

None.

\section{Conflicts of interest}

The authors declare that no conflict of interest exists.

\section{References}

1. Guidelines for the treatment of malaria. 3rd Edn. 2015.

2. World Health Organization (WHO). Guidelines for the treatment of malaria. $2^{\text {nd }}$ Ed. Swizerland; 2010.

3. Otuechere CA, Edewor G, Kale OE, et al. Sub-acute therapeutic dosing of artemether-lumefantrine and artesunate-amodiaquine combination preserves plasma cholesterol, renal antioxidant status, and organ weights in rats. Malar Res Treat. 2012;2012:257986

4. Arun R, Smith A. Development of analytical method for lumefantrine by UV spectrophotometry. International Journal Research Pharmaceutical Sciences. 2011;1(3):321-324

5. Price RN, Douglas NM. Artemisinin combination therapy for malaria: Beyond good efficacy. Clin Infect Dis. 2009;49(11):1638-1640.

6. Little RJ, Pestano AA, Parra Z. Modeling of peroxide activation in artemisinin derivatives by serial docking. J Mol Model. 2009;15: 847858 .
7. World Health Organization WHO. World malaria report. 2014

8. Daikwo OA, Mohammed U Kawu, Rabiu A Magaji, et al. Effect of prolonged administration of artemether-lumefantrine on testicular biomarkers of oxidative stress: Ameliorative effect of vitamin E. Basic Sciences of Medicine. 2018;7(1):1-6.

9. Madiha AA, Abeer AAshry, F Abd Ellah, et al. The possible ameliorative effect of propolis in rats liver treated with monosodium glutamate. Natural Science. 2012;10:209-219.

10. Amal A Afeefy, Marwa S Mahmoud, Mona AA Araf. Effect of honey on monosodium glutamate induced nephrotoxicity. Journal of American Science. 2012;8(1):1-11.

11. Akanya HO, S Peter, IF Ossamulu, et al. Evaluation of the changes in some liver function and haematological parameters in monosodium glutamate fed rats. International Journal of Biochemistry Research and Review. 2015;6(3):113-120.

12. Ajibade AJ, Fakunle PB, Mene AA, et al. Some cardioprotective effects of aqueous extract of ginger against monosodium glutamate induced toxicity in the heart of male Wistar rats. International Journal of Recent Scientific Research. 2013;4(6):972-978.

13. Thomas M, Sujatha KS, George S. Protective effect of Piper longum Linn on monosodium glutamate-induced oxidative stress in rats. Indian J Exp Biol. 2009;47(3):186-192.

14. Okwudiri OO, Alisi Chinwe Sylvanus, Ihetuge Adaeze Peace. Monosodium glutamate induces oxidative stress and affects glucose metabolism in the kidney of rats. International Journal of Biochemistry Research \& Review. 2012;2:1-11.

15. Nakanishi Y, Tsuneyama K, Fujimoto M, et al. Monosodium glutamate: A villain and promoter of liver inflammation and dysplasia. $J$ Autoimmun. 2008;30(1-2):42-50.

16. Egbuonu ACC, CA Ezeokonkwo, PM Ejikeme, et al. Some biochemical effects of sub-acute oral administration of L-arginine on monosodium glutamate fed Wistar albino rats 2: Serum alkaline phosphatase, total acid phosphatase and aspartate aminotransferase activities. Asian Journal of Biochemistry. 2010;5(2):89-95.

17. Egbuonu ACC, O Obidoa, CA Ezeokonkwo, et al. Some biochemical effects of subacute oral administration of L-arginine on monosodium glutamate fed Wistar albino rats 1: body weight changes, serum cholesterol, creatinine and sodium ion concentrations. Toxicological and Environmental Chemistry. 2010;92(7):1331-1337.

18. Chandra K, Ali Syed Salman, Abid Mohd, et al. Protection against FCA induced oxidative stress induced DNA damage as a model of arthritis and in vitro antiarthritic potential of Costus speciosus rhizome extract. International Journal of Pharmacognosy and Phytochemical Research. 2015;7(2):383-389.

19. Parellada M, Moreno C, Mac-Dowell K, et al. Plasma antioxidant capacity is reduced in Asperger syndrome. $J$ Psychiatr Res. 2012;46(3):394-401.

20. Hwang O. Role of oxidative stress in Parkinson's disease. Exp Neurobiol. 2013;22(1):11-17.

21. Roma Mateo C, Aguado C, Garcia Gimenez JL, et al. Increased oxidative stress and impaired antioxidant response in lafora disease. Molecular Neurobiology. 2015;51(3):932-946.

22. Ramond A, Godin-Ribuot D, Ribuot C, et al. Oxidative stress mediates cardiac infarction aggravation induced by intermittent hypoxia. Fundam Clin Pharmacol. 2013;27(3):252-261.

23. Elaine NM, Katja M, Human anatomy and physiology. $9^{\text {th }}$ Edn. New mastering $\mathrm{A}$ and $\mathrm{P}$ with Pearson E text. Benjamin-Cummings pub co. 2012 .

Citation: Obi E, Egbuonu ACC. Changes in the liver histomorphology, catalase and glutathione peroxidase activity in the serum and liver homogenate of normal and monosodium glutamate-intoxicated rats co-treated with artemether-lumefantrine. Int J Mol Biol Open Access. 20I9;4(2):67-73. DOI: 
24. Abdel-misih S, Bloomston M. Liver anatomy. Surg Clin North Am. 2010;90(4):643-53.

25. Mhamdi A, Queval G, Chaouch S, et al. Catalase function in plants: a focus on Arabidopsis mutants as stress-mimic models. J Exp Bot. 2010;61(15):4197-4220.

26. Akanbi OM, Odaibo AB, Afolabi KA, et al. Effect of self-medication with antimalarial drugs on malaria infection in pregnant women in South-Western Nigeria. Med Princ Pract. 2005;14(1):6-9.

27. Saidu Y, LS Bilbis, M Lawal, et al. Acute and chronic toxicity studies of crude aqueous extract of Albizzia chevalieriharms (leguminosae). Asian Journal of Biochemistry. 2007;2(4):224-236.

28. Egbuonu ACC, O Obidoa, CA Ezeokonkwo, et al. Hepatotoxic effects of low dose oral administration of monosodium glutamate in male albino rats. African Journal of Biotechnology. 2009;8(13):3031-3035.

29. Gbouri N, Presis D, Sattar N. Liver enzymes, nonalcoholic fatty liver disease and incident cardiovascular disease: A narrative review and clinical perspective of prospective data. Hepatology. 2010;52(3):11561161 .

30. Egbuonu ACC, Orijii SO. Pulverized Mangiferaindica(mango) seed kernel mitigated monosodium glutamate intoxicated rats kidney histology and bio-functions. J Nutrition Health Food Sci. 2017;5(1):17.

31. Mbah UO, Egbuonu ACC. Ethanolic extract of Solanum melongena Linn fruit mitigated monosodium glutamate-induced oxidative stress. International Journal of Biochemistry Research \& Review. 2017;18(2):1-8.

32. Mbah UO, Egbuonu ACC. Ameliorative potentials of egg plan (Solanum melongena Linn) fruit ethanolic extract on monosodium glutamate intoxicated rats lipid profile, haematology and heart histology. International Journal of Biochemistry Research \& Review. 2017;18(3):1-10

33. Egbuonu ACC, Ekwuribe GA. Pulverized Mangiferaindica (mango) seed kernel modulated serum lipid profile in monosodium glutamate challenged rats. Journal of Applied Biotechnology. 2017;5(2):72-87.

34. Sinha AK. Colorimetric assay of catalase. Anal Biochem. 1972;47(2):389-394

35. Paglia DE, Valentine WN. Studies on the quantitative and qualitative characterization of erythrocyte glutathione peroxidase. J Lab Clin Med. 1968;70(1):158-169.

36. Egbuonu ACC, Ejike GE. Effect of pulverized Mangifera indica (mango) seed kernel on monosodium glutamate-intoxicated rats' serum antioxidant capacity, brain function and histology. EC Pharmacology and Toxicology. 2017;4(6):228-243.

37. Egbuonu ACC, Nzewi DC. Effect of blanching prior to oven drying on some functional composition of bitter yam (Dioscorea dumetorum). Research Journal of Medicinal Plants. 2014;8(5):231-238.
38. Egbuonu ACC, Daniel C Nzewi, Onyinye Nikru C Egbuonu. Effect of soaking prior to oven drying on some nutrient and anti-nutrient properties of bitter yam (Dioscorea dumetorum). Journal of Nutrition and Food Science. 2014

39. Egbuonu ACC, DC Nzewi, ONC Egbuonu. Functional properties of bitter yam (Dioscorea dumetorum) as influenced by soaking prior to oven drying. American Journal of Food Technology. 2014;9(2):97-103.

40. Lopez Alarcon C, Denicola A. Evaluating the antioxidant capacity of natural products: A review on chemical and cellular-based assays. Analytical Chimica Acta. 2013;763:1-10.

41. Saurai P. Silymarin as a natural antioxidant: An overview of the current evidence and perspectives. Antioxidants. 2015;4(1):204-247.

42. Egbuonu ACC, Chinazum I Opara, Okechukwu C Atasie, et al. Vitamins composition and antioxidant properties in normal and monosodium glutamate-compromised rats' serum of avocado pear (Pearsea americana) seed. Open Access Journal of Chemistry. 2017;1(1):19-24.

43. Abolaji AO, Eteng MU, Omonua O, et al. Influence of co-administration of artemether and lumefantrine on selected plasma biochemical and erythrocyte oxidative stress indices in female Wistar rats. Hum Exp Toxicol. 2012;32(2):206-215.

44. Idowu ET, CG Alimba, EA Olowu, et al. Artemether-Lumefantrine treatment combined with albendazole and ivermectin induced genotoxicity and hepatotoxicity through oxidative stress in Wistar rats. Egyptian Journal of Basic and Applied Sciences. 2015;2(2):110-119.

45. Adaramoye OA, Osaimoje DO, Akinsanya AM, et al. Changes in antioxidant status and biochemical indices after acute administration of artemether, artemether-lumefantrine and halofantrine in rats. Basic Clin Pharmacol Toxicol. 2008;102(4):412-418.

46. Manal ST, Nawal A. Adverse effects of monosodium glutamate on liver and kidney function in adult rats and potential protective effect of vitamins C and E. Food and Nutrition Sciences. 2012;3(5):651-659.

47. Ukwenya VO. Acute administration of co-artesiane induces oxidative stress in the testes of adult male Wistar rats. Bioscience Research Communication. 2010;22(5):259-265.

48. Ariano MA, Wagle N, Grissell AE. Neuronal vulnerability in mouse models of Huntington's disease: Membrane channel protein changes. $J$ Neurosci Res. 2005;80(5):634-645.

49. Punitha R, Manoharan S. Antihyperglycemic and antilipidperoxidative effects of Pongamia pinnata (Linn.) Pierre flowers in alloxan induced diabetic rats. Journal of Ethnopharmacology. 2006;105(1-2):39-46.

50. Akomolafe RO, Isaac OlukayodeAdeoshun, Julius BayoFakunle, et al. Effects of artemether on biochemical markers of liver function in Plasmodium berghei-infected and non-infected rats. African Journal of Biotechnology. 2013;12(11):1275-1287.

Citation: Obi E, Egbuonu ACC. Changes in the liver histomorphology, catalase and glutathione peroxidase activity in the serum and liver homogenate of normal and monosodium glutamate-intoxicated rats co-treated with artemether-lumefantrine. Int J Mol Biol Open Access. 20I9;4(2):67-73. DOI: 